\title{
Information technology's impact on productivity in conventional power plants
}

\author{
Madjid Tavana* \\ Management Information Systems \\ La Salle University \\ Philadelphia, PA 19141, USA \\ E-mail: tavana@lasalle.edu \\ *Corresponding author
}

\section{Mohammad H. Khakbaz}

Department of Industrial Engineering

Tarbiat Modares University

Tehran, Iran

E-mail: Hosein.khakbaz@yahoo.com

\section{Mohsen Jafari-Songhori}

Department of Industrial Engineering

University of Tehran

Tehran, Iran

E-mail: mh_jafary@yahoo.com

\begin{abstract}
The economy has undergone a profound structural transformation in the last two decades. The Information Technology (IT) revolution has expanded well beyond the cutting-edge high-tech sector redefining the rules of global competition. In general, a direct correlation between IT spending and organisational productivity (often referred to as the 'productivity paradox') has been very elusive. Numerous studies have been undertaken to either explain or dispel this paradox. While findings from earlier studies have been conflicting, recent firm-level studies indicate that IT investment has a positive impact on productivity. Data Envelopment Analysis (DEA) has been widely used to evaluate the comparative efficiencies of production processes. We propose a two-stage DEA model to decompose the IT investment impacts on productivity in the power plant industry. IT plays an important role in the effective and efficient generation of electricity in conventional power plants. The proposed model allows the integration of production performance and investment performance and provides management with a comprehensive performance evaluation system. We also propose a benchmarking model in conjunction with our DEA model to measure performance against the 'best-in-class'. The data from 20 public conventional power plants in Iran are used to illustrate and validate our model.
\end{abstract}

Keywords: data envelopment analysis; DEA; information technology; productivity paradox; power plant; Iran; efficiency. 
Reference to this paper should be made as follows: Tavana, M., Khakbaz, M.H. and Jafari-Songhori, M. (2009) 'Information technology's impact on productivity in conventional power plants', Int. J. Business Performance Management, Vol. 11, No. 3, pp.187-202.

Biographical notes: Dr. Madjid Tavana is Professor of Management Information Systems and the Lindback Distinguished Chair of Information Systems at La Salle University where he served as the Chairman of the Management Department and Director of the Center for Technology and Management. He has been a Distinguished Faculty Fellow at NASA's Kennedy Space Center, NASA's Johnson Space Center, Naval Research Laboratory - Stennis Space Center and Air Force Research Laboratory. In 2005, he was awarded the prestigious Space Act Award by NASA. He holds an MBA, a PMIS, and a PhD in Management Information Systems and received his Postdoctoral Diploma in Strategic Information Systems from the Wharton School of the University of Pennsylvania. He is the Editor-in-Chief for the International Journal of Applied Decision Sciences and the International Journal of Strategic Decision Sciences. He has published in journals such as Decision Sciences, Interfaces, Information Systems, Information and Management, Computers and Operations Research, Journal of the Operational Research Society and Advances in Engineering Software, among others.

Mohammad Hossein Khakbaz is a Lecturer at the Azad Islamic University in Iran. He has been a Distinguished Researcher at several Iranian banking research and development centers. He received his Master in Social and Economic Systems Engineering from Tarbiat Modares University and his Bachelor in Industrial Engineering from Iran University of Science and Technology. He has published in the International Journal of Logistics Systems and Management, International Journal of Advanced Manufacturing Technology and International Journal of Information Systems and Change Management.

Mohsen Jafari-Songhori is an Information Technology Consultant and Project Planner at NIPEC. He received his Master of Science in Industrial Engineering from University of Tehran and his Bachelor of Science in Industrial Engineering from Sharif University of Technology. He has published in the International Journal of Production Research, International Journal of Advanced Manufacturing Technology, International Journal of Business Information Systems and International Journal of Logistics Systems and Management.

\section{Introduction}

The increasing intensity of domestic and global competition has led organisations to search for more efficient and effective ways to manage their businesses. Many organisations have turned to Information Technology (IT) to help cope with this turbulent environment (Scott, 2000). Organisations have invested billions of dollars in IT over the past two decades and technology has become a major driver of economic change in the new millennium. While organisations continue to invest heavily in IT, there is much 
debate about the changing role of technology in organisations and the benefits accruing from the investment in IT. The high expenditures in technology and the growing usage that penetrates to the core of organisations have resulted in a need for evaluating the productivity impacts of IT (Chen et al., 2006; Love et al., 2004).

There have been numerous approaches to assessing the performance impact of IT investments (often referred to as the 'productivity paradox'). The debate over the productivity paradox has raged for a long time but the overall analysis suggests that IT does in fact create business value (Brynjolfsson, 1993; Brynjolfsson and Hitt, 1996; Brynjolfsson and Hitt, 2000; Triplett, 1999; Gordon, 2002; Kohli and Devaraj, 2003; Stratopoulos and Dehning, 2000). Value from IT arises not only directly but also indirectly through many means. IT interacts with the organisational processes and alters the relationship of the firm with the external world by altering the competitive conditions. Because the benefits of IT are disperse and arise through several channels, they have been measured at various levels (firm, process and resources) using different measures.

At the firm level, the key question is how IT initiatives affect firm performance. Most researchers believe that IT investments create excess return over other types of capital investments in production processes of firms (Brynjolfsson and Hitt, 1998; Brynjolfsson and Hitt, 1996; Brynjolfsson and Yang, 1996; Dewan and Min, 1997; Dos Santos et al., 1993; Hitt and Brynjolfsson, 1996; Im et al., 2001; Lehr and Lichtenberg, 1999; Richardson and Zmud, 2002; Siegel, 1997; Subramani and Walden, 2001). At the process level, the focus is on the impact of IT investments on specific processes. The process-based view believes that IT investments create competitive advantages by improving operational efficiency of intermediary business processes which in turn, lead to better firm-level performance (Barua et al., 1995; El Sawy, 2001; Mooney et al., 1996; Ray et al., 2005; Soh and Markus, 1995).

The resource-based view believes that IT investments improve firm performance by creating sustainable competitive advantage through unique strategic resources and capabilities (Bharadwaj, 2000; Clemons and Row, 1991; Mata et al., 1995; Powell and Dent-Micallef, 1997; Sambamurthy et al., 2003). In general, while direct correlation between IT spending and organisational productivity is very elusive, many researchers point to organisational complements such as new business processes, new skills, new organisational and industry structures as driving forces contributing to IT impact on productivity and suggest that IT has made a much larger real contribution to the economy than previously believed (Brynjolfsson and Hitt, 2000).

We use Data Envelopment Analysis (DEA) to study the impacts of IT investment on productivity. Most of the published applications of DEA assume a single-stage production process. However, many production processes such as IT investments have more than one stage. Chen et al. (2006) show that a detailed model is needed to characterise the impact of IT on each stage of the business operation. We use a two-stage DEA model, as suggested by Chen et al. (2006), to examine the impacts of IT investment on productivity in the power plant industry. The proposed model allows integration of the production performance and investment performance and provides management with a comprehensive performance evaluation system. The data from 20 public conventional power plants in Iran is used to illustrate and validate our model. 
The remainder of the paper is organised as follows. The next section discusses applications of DEA in IT investment analysis followed by a discussion of the IT impacts on productivity in power plant industry in Section 3. Section 4 presents the details of our mathematical model followed by an illustration of our case study in Section 5 and conclusions in Section 6.

\section{Applications of DEA in IT investment analysis}

DEA is a mathematical programming approach that generalises the Farrell (1957) single-input/single-output technical efficiency measure to multiple-input/multiple-output case to evaluate the relative efficiency of a set of units with respect to multiple performance measures (Charnes et al., 1995). DEA originally was developed by Charnes et al. (1978) and was extended by Banker et al. (1984) to include variable returns to scale. The basic DEA models are known as CCR and BCC. DEA is particularly useful when the relationship among the performance measures is unknown. Through the optimisation for each individual unit, DEA yields an efficient frontier or tradeoff curve that represents the relations among the multiple performance measures. Unlike parametric methods which require detailed knowledge of the production process, DEA is non-parametric and does not require an explicit functional form relating inputs and outputs.

There have been some attempts in the literature to use DEA for understanding the impacts of IT investments on performance and productivity. Banker et al. (1990) used basic DEA models with statistical tests to compare the performance of Hardee's restaurants which had invested heavily in IT with those restaurants with no special investment in technology. They used the random inefficiency results obtained from the DEA model to show that IT helped to reduce input material costs at Hardee's restaurants. Kauffman and Weill (1989) suggested that the impact of IT on firm profitability for the airline industry is indirect. They showed how IT, primarily used for reservations in airline companies, directly impacts market share, which in turn, together with other factors impacts profitability. The three inputs related to investments in their IT study included: IT budget as a percentage of sales, an organisation's total processor value as a percentage of sales, and the percentage of the IT budget allocated to training.

Researchers studying the indirect impact of IT on productivity, argue that investments in IT should provide information that can be used to increase revenues and/or permit the organisations to improve their operating efficiency leading to higher profitability and performance measures related to growth in revenues and profits selected as output measures. After determining which are efficient and inefficient organisations, these organisations can then be studied in-depth based on the input and output criteria. Such a research plan should help researchers work towards the development of a comprehensive theory of IT investment and its relationship to other organisational variables. Wang et al. (1997) utilised DEA to study the marginal benefits of IT with respect to a two-stage process in the firm-level banking industry. In their approach, they viewed firm-level outputs in the context of a series of value added activities and concentrated their attention on IT-related value-added activities. They identified IT effects on intermediate output variables and then related the effects of IT-produced intermediate output variables to 
firm performance. In an attempt to improve the former method, Chen and Zhu (2004) presented a single DEA model that identified the efficient frontier of a two-stage production process linked by intermediate measures.

Dasgupta et al. (1999) showed some limitations of the parametric techniques in investigating the impact of IT investment on firm productivity. They used different DEA models with non-parametric statistical tests to resolve the productivity paradox in firms. Their results showed a negative impact of IT on firm performance. Shafer and Byrd (2000) developed a framework for evaluating the efficiency of IT investment based on a DEA model. Their proposed methodology considered the issue of time lags between investments in IT and the accrual of benefits associated with these investments. Moreover, they considered the issue of redistribution of profits by using the organisation's performance relative to the performance of its industry group.

Seiford and Zhu (1999) suggested using the two-stage DEA method and divided a commercial bank's production process into two stages, marketability and profitability. The marketability stage focused on three inputs (employees, assets and shareholders' equity) and two outputs (revenues and profits). The second stage used the outputs of the first stage (revenues and profits) as its inputs, and used market value, total investment returns and earnings per share as the outputs to measure the profitability. Zhu (2000) followed up the two-stage DEA method introduced by Seiford and Zhu (1999) and used it to analyse the financial efficiency of the best 500 companies ranked by Fortune magazine. The methods used in the first and second stages were similar to those of Seiford and Zhu (1999). The marketability measures in the first stage included three inputs (employees, assets and shareholders' equity) and two outputs (revenues and profits). The profitability measures in the second stage included two inputs (which were the outputs in the first stage: revenues and profits) and three outputs (market value, total investment returns and earnings per share).

Sexton and Lewis (2003) used a two-stage DEA model for major league baseball and demonstrated its advantages over the standard DEA models. Their model detected inefficiencies that standard DEA models missed. The inefficiencies distinguished in the first stage allowed managers to target inefficiencies in the production process. Abad et al. (2004) developed a two-stage multi-criteria procedure based on DEA to investigate the relationship between stocks financial data to firm value in two consecutive steps, a predictive information stage tying current financial data to future earnings, and a valuation stage, tying future earnings to firm value. At each stage, a large number of causal factors were factored into the evaluation.

Yang (2006) used a two-stage DEA model to provide valuable managerial insights when assessing the dual impacts of operating and business strategies for the Canadian life and health insurance industry. Yang's (2006) model allowed integration of the production performance and investment performance for the insurance companies and provided management with overall performance evaluation needed to achieve efficiency systematically for the insurers involved.

Some of the limitations of these studies are that they do not explicitly consider the moderating effects of the intermediate variables directly produced by IT and they assume that all firms utilise their IT efficiently. Most of the DEA applications assume that production processes consist of one stage. However, many production processes such as IT investments have more than one stage (Rho and An, 2007). In a two-stage production process, the first stage inputs produce intermediate outputs, which are used as inputs to 
the second stage to produce the final outputs. We use DEA as the fundamental tool in our study for the following reasons. First, in performance evaluation, the use of single measures ignores any interactions among various firm performance measures. DEA has been proven effective in performance evaluation when multiple performance measures are present (Zhu, 2002). Second, DEA does not require a priori information about the relationship among multiple performance measures. Third, a number of studies about the IT impact on firm performance have successfully used DEA (Abad et al., 2004; Banker et al., 1990; Chen and Zhu, 2004; Dasgupta et al., 1999; Kauffman and Weill, 1989; Rho and An, 2007; Seiford and Zhu, 1999; Sexton and Lewis, 2003; Shafer and Byrd, 2000; Wang et al., 1997; Yang, 2006; Zhu, 2000).

\section{IT impacts on productivity in power plant industry}

The standard measure of productivity used in the conventional power plant industry is the ratio of total annual expenditure (operating, maintenance and administration) to total energy produced in megawatt hours (MWH) per year. Total power production, the most convenient and readily available indicator of productive capability, is the principal output of the operation. What may be missing in this simplistic measure of productivity is a consideration of those factors that reflect management's skill.

Golany et al. (1994) used DEA to evaluate the operating efficiency of power plants in the Israeli Electric Corporation. They emphasised the process of screening the list of potential input and output factors and determined the most relevant ones. Park and Lesourd (2000) determined the efficiencies of conventional fuel power plants in South Korea by DEA and stochastic methods. Cook et al. (1998) used the DEA model of Charnes et al. (1978) to evaluate the operational efficiency of power plants by representing efficiency measurement from a hierarchical perspective. In a follow-up study, Cook and Green (2005) presented a methodology for evaluating efficiency in a hierarchical structure with two levels. A shortcoming of this hierarchical approach is that many 'efficient' power units result in the Level 1 analysis. Two factors contribute to this outcome, the small number of units per plant, and the fact that each power unit is free to choose its own multipliers. To rectify the weaknesses in the models of Cook et al. (1998) and Cook and Green (2005), Sarica and Or (2007) used DEA to define and pursue two efficiency indexes reflecting operational and investment performance. Their model analysed performance of 65 thermal, hydro and wind power plants, owned by the private and public sectors in Turkey. Cook and Zhu (2007) extended the DEA structure to examine a set of power plants with a goal-programming model. Their model was applied to a more general setting where Decision-making Units (DMUs) fell into distinct groups, and where all members of a group were to be treated uniformly in terms of multiplier allocation.

We propose a two-stage DEA model to study the impact of IT expenditures on conventional power plants performance in Iran. We decompose the inputs of IT investment in the first stage into the second stage. The resulting model is a non-linear DEA program which can be solved as a parametric linear program. This new model not only evaluates the impact of IT impact on both stages, but also provides IT investment allocation on both stages. The results can be used in IT budgeting and allocation decisions. The indicators selected in our model are presented below and are similar to those identified by Sarica and Or (2007): 
- Fuel costs are the total annual costs of the fuel used in the plant. Fuel is one of the primary resources used in the generation and delivery of electricity and its inclusion basically eliminates the necessity to consider other monetary factors in the model at the operational level. Fuel costs are considered inputs in the model.

- Availability represents the time period when the power plant is available for producing power. Availability is considered an output in the model.

- Production reflects the annual amount of electricity produced by the power plant. Production is considered an output in the model.

- Thermal efficiency represents the amount of the dissipated heat converted into electric energy. Thermal efficiency has environmental and economic implications such that maximisation of efficiency minimises emissions and fuel consumption simultaneously. Thermal efficiency is considered an output in the model.

\section{Mathematical model and notations}

In this study, we propose a two-stage DEA model, with an availability stage (Stage I) and a production stage (Stage II), where:

- Fuel costs are divided into two parts: $\alpha F$ and $(1-\alpha) F$ for Stages I and II.

- $\quad$ IT costs are divided into two parts: $\beta I$ and $(1-\beta) I$ for Stages I and II.

- Number of employees are divided into two parts: $\gamma E$ and $(1-\gamma) E$ for Stages I and II, and $\alpha, \beta, \gamma \leq 1$.

Availability (denoted as $A$ ) is the output of Stage I and is one of the inputs in Stage II. $\alpha F, \beta I$ and $\gamma E$ are the inputs of Stage I; and $(1-\alpha) F,(1-\beta) I$ and $(1-\gamma) E$ and $A$ are the inputs of Stage II. Production and thermal efficiency (denoted as $P$ and $T$ ) are the outputs of Stage II. The DEA model for IT investments in conventional power plants is depicted in Figure 1.

Figure 1 Two-stage DEA model (see online version for colours)

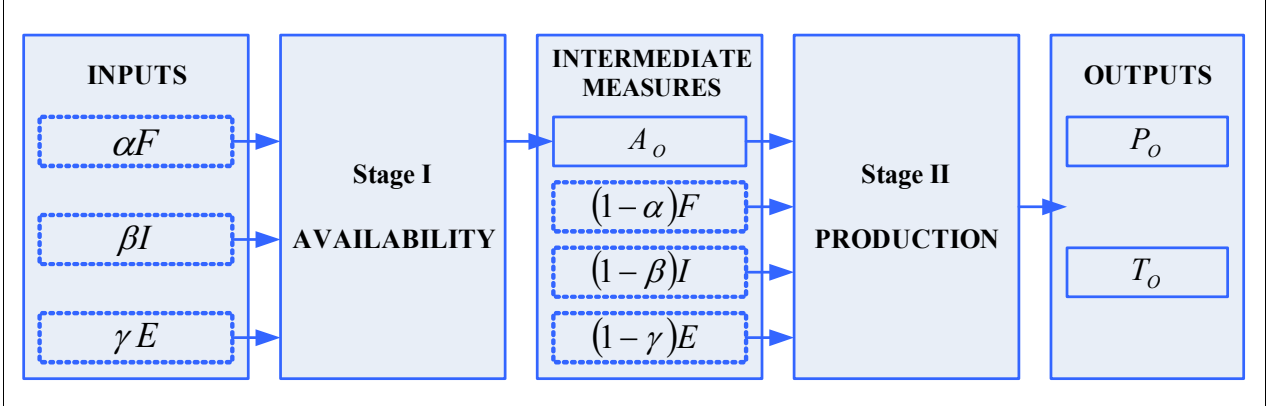


Let us further assume:

$U_{A}=$ the importance weight of availability

$U_{L}^{T}=$ the vector of the importance weights for production and thermal efficiencies

$V_{F}=$ the importance weight of the fuel costs

$V_{I}=$ the importance weight of the IT costs

$V_{E}=$ the importance weight of the number of employees

$\alpha=$ the percentage usage of fuel costs in Stage I

$\beta=$ the percentage usage of IT costs in Stage I

$\lambda=$ the percentage usage of number of employees in Stage I

$F_{O}=$ the fuel costs usage of the DMUs for the efficiency run

$I_{O}=$ the IT costs usage of the DMUs for the efficiency run

$E_{O}=$ the employee usage of the DMUs for the efficiency run

$A_{O}=$ the availability output of Stage I during the efficiency run

$P_{O}=$ the production output of Stage II for the efficiency run

$T_{O}=$ the thermal output of Stage II for the efficiency run

$F_{J}=$ the fuel costs input for the $J$-th $\operatorname{DMU}(J=1,2, \ldots n)$

$I_{J}=$ the IT costs input for the $J$-th DMU $(J=1,2, \ldots n)$

$E_{J}=$ the number of employees input for the $J$-th DMU $(J=1,2, \ldots n)$

$A_{J}=$ the availability output of Stage I for the $J$-th DMU $(J=1,2, \ldots n)$

$P_{J}=$ the production output of Stage II for the $J$-th DMU $(J=1,2, \ldots n)$

$T_{J}=$ the thermal output of Stage II for the $J$-th DMU $(J=1,2, \ldots n)$

$n=$ the total number of DMUs

$U_{L}=$ the upper limit for the ratio of allocated input in Stage I to respected input in Stage II

$L_{L}=$ the lower limit for the ratio of allocated input in Stage I to respected input in Stage II.

We use the model developed by Chen et al. (2006) during the initial stage:

$$
\operatorname{Max} \frac{1}{2}\left[\frac{U_{A} A_{O}}{V_{F} \alpha F_{O}+V_{I} \beta I_{O}+V_{E} \lambda E_{O}}+\frac{U_{L}^{T}\left(\begin{array}{c}
P_{O} \\
T_{O}
\end{array}\right)}{V_{F}(1-\alpha) F_{O}+V_{I}(1-\beta) I_{O}+V_{E}(1-\lambda) E_{O}+U_{A} A_{O}}\right] .
$$

Subject to:

$$
\frac{U_{J} A_{J}}{V_{F} \alpha F_{J}+V_{I} \beta I_{J}+V_{E} \lambda E_{J}} \leq 1,
$$




$$
\begin{aligned}
& \frac{U_{L}^{T}\left(\begin{array}{c}
P_{J} \\
T_{J}
\end{array}\right)}{V_{F}(1-\alpha) F_{J}+V_{I}(1-\beta) I_{J}+V_{E}(1-\lambda) E_{J}+U_{A} A_{J}} \leq 1, \\
& \alpha \geq 0 \text { and } \beta, \lambda \leq 1, \\
& V_{F}, V_{I}, V_{E}, U_{A}, U_{L}^{T} \geq 0 .
\end{aligned}
$$

However, as stated by Chen et al. (2006), IT costs, fuel costs and number of employees might be allocated to one specific stage only. We impose additional constraints to $\alpha, \beta$ and $\gamma$ to ensure that both stages are assigned IT costs, fuel costs and number of employees. Since $\frac{w_{L F}^{\prime}}{w_{D F}^{\prime}}=\frac{w_{L I}^{\prime}}{w_{D I}^{\prime}}=\frac{w_{L E}^{\prime}}{w_{D E}^{\prime}}=\frac{c_{L}}{\mu_{A}}=k$, we can impose such constraints using $\frac{c_{L}}{\mu_{A}} \geq L_{L}$, and $\frac{c_{L}}{\mu_{A}} \leq U_{L}$ where $L_{L}$ and $U_{L}$ are the lower and upper limits for the ratio of allocated input (e.g., IT investment) in Stage I to the amount of input in Stage II. The resulting availability efficiency $\left(\mu_{A} A_{O}\right)$, production efficiency $\left(\mu_{L}^{T}\left(\begin{array}{l}P_{O} \\ T_{O}\end{array}\right)\right)$, and average efficiency can be used as a dependent variable to study how and why some organisations use IT more effectively.

$$
\operatorname{Max} \frac{1}{2}\left[\mu_{A} A_{O}+\mu_{L}^{T}\left(\begin{array}{c}
P_{O} \\
T_{O}
\end{array}\right)\right] \text {. }
$$

Subject to:

$$
\begin{aligned}
& \frac{c_{L}}{\mu_{A}} w_{D F}^{\prime} F_{J}+\frac{c_{L}}{\mu_{A}} w_{D I}^{\prime} I_{J}+\frac{c_{L}}{\mu_{A}} w_{D E}^{\prime} E_{J}-\mu_{A} A_{J} \geq 0 \\
& \frac{c_{L}}{\mu_{A}} w_{D F}^{\prime} F_{O}+\frac{c_{L}}{\mu_{A}} w_{D I}^{\prime} I_{O}+\frac{c_{L}}{\mu_{A}} w_{D E}^{\prime} E_{O}=\frac{c_{L}}{\mu_{A}} \\
& w_{L F}^{\prime} F_{J}+w_{L I}^{\prime} I_{J}+w_{L E}^{\prime} E_{J}+c_{L} A_{J}+C_{L} D_{J}-\mu_{L}^{T}\left(\begin{array}{c}
P_{J} \\
R_{J}
\end{array}\right) \geq 0 \\
& w_{L F}^{\prime} F_{O}+w_{L I}^{\prime} I_{O}+w_{L E}^{\prime} E_{O}+c_{L} A_{O}=1 \\
& w_{L F}^{\prime}, w_{L I}^{\prime}, w_{L E}^{\prime}, w_{D F}^{\prime}, w_{D I}^{\prime}, w_{D E}^{\prime}, \mu_{A}, c_{L}, \mu_{L}^{T} \geq 0 \quad \text { for } J=1,2, \ldots, n .
\end{aligned}
$$

\section{Case study}

We used the model presented in Section 4 to study IT investment impacts on productivity in 20 public conventional power plants built between 1967 and 2006 in Iran. ${ }^{1}$ All power plants are fossil fuel plants that burn diesel, oil and/or natural gas to produce electricity. These power plants are designed on a large scale for continuous operations and provide most of the electrical energy in Iran. This study was conducted for the Iranian 
government who was interested in expanding their traditional definition of productivity (the ratio of total production in megawatt hours to total expenditure) to encompass other factors such as the IT budget and the number of employees. Table 1 presents the start-up year, IT budget, fuel costs and the number of employees for each power plant. The average IT budget, fuel costs and number of employees for 2001 and 2002 were used as the input in the model. As suggested by Shafer and Byrd (2000), we considered time lag between IT investment and performance and used the average performance for 2003-2007 as the output indicators in this study. We also used the number of employees in lieu of wages and salaries to avoid mixing up other efficiencies (i.e., human resource management efficiency) with our desirable IT efficiency.

Table 1 Conventional power plants in Iran and their specifications

\begin{tabular}{lcccc}
\hline Plant number & Start-up year & $\begin{array}{c}\text { IT budget } \\
\text { (\$ billion) }\end{array}$ & $\begin{array}{c}\text { Fuel costs } \\
\text { (\$ billion) }\end{array}$ & $\begin{array}{c}\text { Number of employees } \\
\text { (thousand) }\end{array}$ \\
\hline 1 & 1967 & 0.322 & 0.525 & 10.975 \\
2 & 1969 & 0.336 & 0.908 & 15.032 \\
3 & 1973 & 0.274 & 0.702 & 8.555 \\
4 & 1973 & 0.079 & 0.712 & 40.981 \\
5 & 1973 & 0.197 & 0.385 & 30.842 \\
6 & 2005 & 0.472 & 0.283 & 3.617 \\
7 & 1979 & 0.244 & 0.673 & 3.582 \\
8 & 1980 & 0.340 & 0.966 & 10.057 \\
9 & 1984 & 0.742 & 0.884 & 23.349 \\
10 & 2006 & 0.450 & 0.528 & 16.188 \\
11 & 1986 & 0.258 & 0.927 & 2.079 \\
12 & 1992 & 0.131 & 1.807 & 5.262 \\
13 & 1994 & 1.013 & 0.998 & 8.049 \\
14 & 1994 & 0.349 & 0.521 & 11.758 \\
15 & 1998 & 0.319 & 1.060 & 3.057 \\
16 & 2000 & 0.127 & 3.438 & 6.192 \\
17 & 1977 & 0.108 & 1.224 & 6.085 \\
18 & 1981 & 1.307 & 4.510 & 14.861 \\
19 & 1971 & 0.291 & 2.473 & 11.23 \\
20 & 1986 & 0.715 & 1.932 & 0.595 \\
\hline
\end{tabular}

Table 2 presents the results from the two-stage DEA model. The second column reports availability $\left(A_{o}\right)$, the third column reports production $\left(P_{o}\right)$, and the fourth column reports thermal efficiency $\left(T_{o}\right)$. Equations (6) through (11) were used to maximise average efficiency. Availability, production, and average efficiencies are presented in Columns 5, 6 and 7 of Table 2. As it is shown in this table, power plant 18 has the highest average efficiency (1.129) and power plant 2 has the lowest average efficiency $(0.800)$. A graphical representation of the availability, production and average efficiencies are presented in Figure 2. Power plants 9, 10,13 and 18 are the most efficient power plants. 
Table 2 Results of the two-stage DEA model

\begin{tabular}{lcrcccc}
\hline \multirow{2}{*}{$\begin{array}{l}\text { Plant } \\
\text { number }\end{array}$} & $A_{o}$ & \multicolumn{1}{c}{$P_{o}$} & $T_{o}$ & Availability & Production & Average \\
\hline 1 & 50.38 & 5193264 & 30.15 & 0.878 & 0.783 & 0.831 \\
2 & 36.85 & 3236242 & 27.34 & 0.765 & 0.835 & 0.800 \\
3 & 30.7 & 2329942 & 33.69 & 0.862 & 0.963 & 0.913 \\
4 & 23.84 & 1158271 & 51.66 & 0.784 & 0.962 & 0.873 \\
5 & 29.59 & 1910901 & 77.81 & 0.987 & 0.776 & 0.882 \\
6 & 73.65 & 6910827 & 24.77 & 0.864 & 1.106 & 0.985 \\
7 & 23.78 & 1458074 & 42.93 & 0.768 & 0.964 & 0.866 \\
8 & 43.37 & 4919855 & 55.55 & 0.945 & 0.846 & 0.896 \\
9 & 87.36 & 7772392 & 67.21 & 1.112 & 1.024 & 1.068 \\
10 & 34.89 & 4167909 & 39.28 & 0.924 & 1.080 & 1.002 \\
11 & 28.5 & 2041854 & 41.19 & 0.776 & 0.925 & 0.850 \\
12 & 12.06 & 955763 & 67.26 & 0.776 & 0.926 & 0.851 \\
13 & 91.7 & 9385477 & 33.71 & 1.060 & 0.998 & 1.029 \\
14 & 44.39 & 3097138 & 35.14 & 0.896 & 0.928 & 0.912 \\
15 & 26.95 & 3202072 & 76.72 & 0.893 & 0.974 & 0.933 \\
16 & 12.43 & 839996 & 60.39 & 0.789 & 0.923 & 0.856 \\
17 & 14.34 & 748051 & 49.99 & 0.818 & 0.920 & 0.869 \\
18 & 41.39 & 11602231 & 43.44 & 1.220 & 1.039 & 1.129 \\
19 & 38.08 & 2318532 & 50.22 & 0.898 & 0.803 & 0.851 \\
20 & 9.097 & 207541 & 55.84 & 0.787 & 0.868 & 0.827 \\
\hline & & & & & &
\end{tabular}

Next, we produced a graph with availability efficiency as the ' $\mathrm{X}$-axis' and production efficiency as the 'Y-axis'. The mean availability and efficiency indices divided the graph into four zones: efficient organisations, inefficient organisations, producers and enablers. Efficient organisations are those with high availability and high production efficiencies while inefficient organisations are those with low availability and low production efficiencies. Producers are those organisations with high production efficiency and low availability efficiency while enablers are those organisations with high availability efficiency and low production efficiency. As shown in Figure 3, given the average availability efficiency of 0.897 and average production efficiency of 0.932 , power plants $9,10,13$ and 18 are considered efficient organisations while power plants 1,11 , $12,14,16,17$ and 20 are considered inefficient organisations. Furthermore, power plants $3,4,6,7$ and 15 are considered producers while 2, 5, 8 and 19 are enablers. 
Figure 2 Power plant efficiencies (see online version for colours)

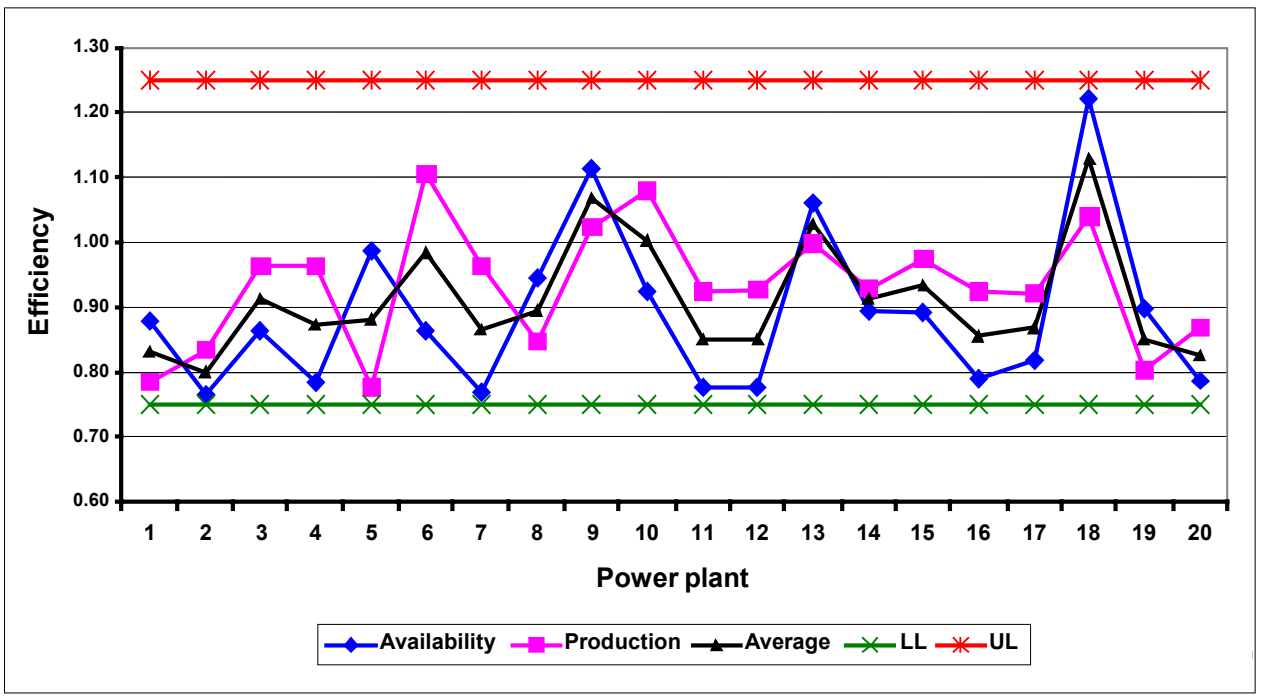

Figure 3 Benchmarking model (see online version for colours)

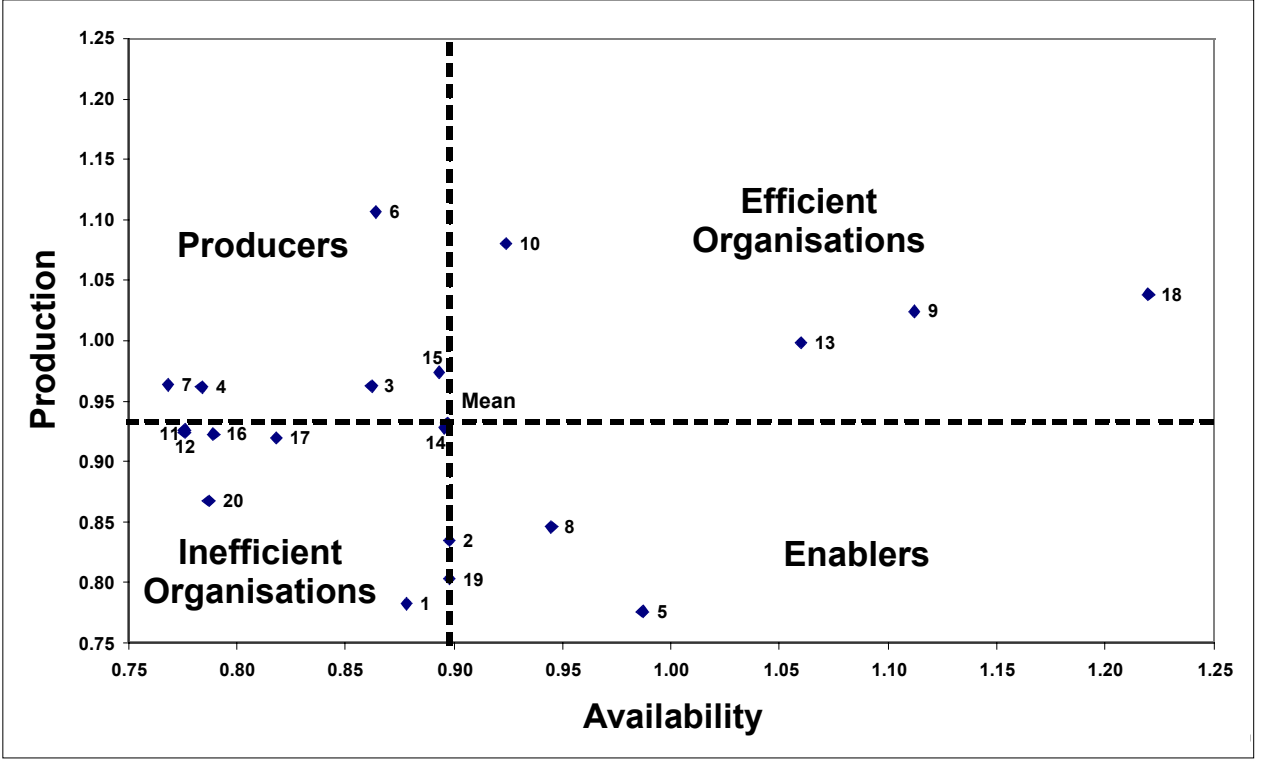

Finally, we performed a correlation analysis to study the effect of the IT budget, fuel costs and the number of employees on availability, production and average efficiencies. Correlation is a bivariate measure of association (strength) of the relationship between two variables and it varies from 0 (random relationship) to 1 (perfect linear relationship) or -1 (perfect negative linear relationship). As it is shown in Table 3 , the IT budget has the highest impact on availability and production efficiencies and consequently on the average efficiency. Contrary to IT investment, there is little or no correlation between 
efficiency and fuel costs or the number of employees. The high correlation between IT investments supports the direct impacts of IT investment on productivity and efficiency in conventional power plants in Iran.

Table 3 Correlation coefficient matrix

\begin{tabular}{lccc}
\hline & Availability & Production & Average \\
\hline IT budget & 0.779 & 0.400 & 0.766 \\
Fuel costs & 0.286 & 0.022 & 0.215 \\
Number of employees & 0.275 & -0.082 & 0.152 \\
\hline
\end{tabular}

\section{Conclusion}

The high expenditures in technology and the growing usage that penetrates to the core of organisations have resulted in a need for evaluating the productivity impacts of IT. There have been numerous studies assessing the impact of IT investments on productivity and efficiency. However, direct correlation between IT spending and organisational productivity has been very elusive. We used a two-stage DEA model to decompose IT investment impacts on productivity in 20 public conventional power plants in Iran. The proposed model allowed the integration of production and investment performance, and provided management with a comprehensive performance evaluation system. The results from our correlation analysis indicated that the IT budget has the utmost impact on availability and production efficiencies. Our results indicate that IT plays an important role in the effective and efficient generation of electricity in conventional power plants.

The model proposed in this study could be used as a stand-alone performance assessment system to evaluate the impact of IT on productivity or as a benchmarking system. Benchmarking is measuring performance in an organisation against the 'best-in-class'. Practicing managers should be careful when using our benchmarking model since best practices followed by certain successful organisations may not necessarily be the best when adopted by other organisations. Benchmarking is recognised as an essential tool for continuous improvement of quality but the success rate may significantly differ across organisations.

\section{References}

Abad, C., Thore, S.A. and Laffarga, J. (2004) 'Fundamental analysis of stocks by two-stage DEA', Managerial and Decision Economics, Vol. 25, No. 5, pp.231-241.

Banker, R.D., Charnes, A. and Cooper, W.W. (1984) 'Some models for estimating technical and scale inefficiencies in data envelopment analysis', Management Science, Vol. 30, No. 9, pp.1078-1092.

Banker, R.D., Kauffman, R.J. and Morey, R.C. (1990) 'Measuring gains in operational efficiency from information technology: a study of the Positran Deployment at Hardee's Inc.', Journal of Management Information Systems, Vol. 7, No. 2, pp.29-54.

Barua, A., Kriebel, H.C. and Mukhopadhyay, T. (1995) 'Information technologies and business value: an analytic and empirical investigation', Information Systems Research, Vol. 6, No. 1, pp.3-23. 
Bharadwaj, A.S. (2000) 'A resource-based perspective on information technology capability and firm performance: an empirical investigation', MIS Quarterly, Vol. 24, No. 1, pp.169-196.

Brynjolfsson, E. (1993) 'The productivity paradox of information technology', Communications of the ACM, Vol. 36, No. 12, pp.67-77.

Brynjolfsson, E. and Hitt, L.M. (1996) 'Paradox lost? Firm-level evidence on the returns to information systems spending', Management Science, Vol. 42, No. 4, pp.541-558.

Brynjolfsson, E. and Hitt, L.M. (1998) 'Beyond the productivity paradox', Communications of the ACM, Vol. 41, No. 8, pp.49-55.

Brynjolfsson, E. and Hitt, L.M. (2000) 'Beyond computation: information technology, organizational transformation and business performance', Journal of Economic Perspectives, Vol. 14, No. 4, pp.23-48.

Brynjolfsson, E. and Yang, S. (1996) 'Information technology and productivity: a review of the literature', Advances in Computers, Vol. 43, No. 2, pp.179-214.

Charnes, A., Cooper, W.W. and Rhodes, E.L. (1978) 'Measuring the efficiency of decision making units', European Journal of Operational Research, Vol. 2, No. 6, pp.429-444.

Charnes, A., Seiford, L., Cooper, W. and Lewin, A. (1995) Data Envelopment Analysis: Theory, Methodology and Application, Norwell, MA: Kluwer Academic Publishers.

Chen, Y., Liang, L., Yang, F. and Zhu, J. (2006) 'Evaluation of information technology investment: a data envelopment analysis approach', Computers and Operations Research, Vol. 33, No. 5, pp.1368-1379.

Chen, Y. and Zhu, J. (2004) 'Measuring information technology's indirect impact on firm performance', Information Technology and Management, Vol. 5, Nos. 1-2, pp.9-22.

Clemons, E.K. and Row, M.C. (1991) 'Sustaining IT advantage: the role of structural differences', MIS Quarterly, Vol. 15, No. 3, pp.275-292.

Cook, W.D., Chai, D., Green, R.H. and Doyle, J. (1998) 'Hierarchies and groups in DEA', Journal of Productivity Analysis, Vol. 10, No. 2, pp.177-198.

Cook, W.D. and Green, R.H. (2005) 'Efficiency measurement of electric power plants: a hierarchical model', Computers and Operations Research, Vol. 32, No. 4, pp.813-823.

Cook, W.D. and Zhu, J. (2007) 'Within-group common weights in DEA: an analysis of power plant efficiency', European Journal of Operational Research, Vol. 178, No. 1, pp.207-216.

Dasgupta, S., Sarkis, J. and Talluri, S. (1999) 'Influence of information technology investment on firm productivity: a cross-sectional study', Logistics Information Management, Vol. 12, Nos. 1-2, pp.120-129.

Dewan, S. and Min, C. (1997) 'The substitution of information technology for other factors of production: a firm level analysis', Management Science, Vol. 43, No. 12, pp.1660-1675.

Dos Santos, B., Peffers, K. and Mauer, D.C. (1993) 'The impact of information technology investment announcements on the market value of the firm', Information Systems Research, Vol. 4, No. 1, pp.1-23.

El Sawy, O. (2001) Redesigning Enterprise Processes for e-Business, Boston: McGraw-Hill.

Farrell, M.J. (1957) 'The measurement of productive efficiency', Journal of the Royal Statistical Society, Series A (General), Part III, Vol. 120, pp.253-290.

Golany, B., Roll, Y. and Ryback, D. (1994) 'Measuring efficiency of power plants in Israel by data envelopment analysis', IEEE Transactions on Engineering Management, Vol. 41, No. 3, pp.291-301.

Gordon, R.J. (2002) 'Technology and economic performance in the American economy', National Bureau of Economic Research Working Paper \# 8771, Washington, DC.

Hitt, L.M. and Brynjolfsson, E. (1996) 'Productivity, business profitability, and consumer surplus: three different measures of information technology value', MIS Quarterly, Vol. 20, No. 2, pp.121-142. 
Im, K., Dow, K. and Grover, V. (2001) 'Research report: a reexamination of IT investment and the market value of the firm - an event study methodology', Information Systems Research, Vol. 12, No. 1, pp.103-117.

Kauffman, R.J. and Weill, P. (1989) 'An evaluative framework for research on the performance effects of information technology investment', Proceedings of the 10th International Conference on Information Systems, Boston, Massachusetts, pp.377-388.

Kohli, R. and Devaraj, S. (2003) 'Measuring information technology payoff: a meta-analysis of structural variables in firm-level empirical research', Information Systems Research, Vol. 14, No. 2, pp.127-145.

Lehr, B. and Lichtenberg, F.R. (1999) 'Information technology and its impact on productivity: firm-level evidence from government and private data sources, 1977-1993', Canadian Journal of Economics, Vol. 32, No. 2, pp.335-362.

Love, P.E.D., Ghoneim, A. and Irani, Z. (2004) 'Information technology evaluation: classifying indirect costs using the structured case method', The Journal of Enterprise Information Management, Vol. 17, No. 4, pp.312-325.

Mata, F.J., Fuerst, W.L. and Barney, J.B. (1995) 'Information technology and sustained competitive advantage: a resource-based analysis', MIS Quarterly, Vol. 19, No. 4, pp.487-505.

Mooney, J., Gurbaxani, V. and Kraemer, K. (1996) 'A process oriented framework for assessing the business value of information technology', Database for Advances in Information Systems, Vol. 27, No. 2, pp.68-81.

Park, S.U. and Lesourd, J.B. (2000) 'The efficiency of conventional fuel power plants in South Korea: a comparison of parametric and non-parametric approaches', International Journal of Production Economics, Vol. 63, No. 1, pp.59-67.

Powell, T.C. and Dent-Micallef, A. (1997) 'Information technology as competitive advantage: the role of human, business, and technology resources', Strategic Management Journal, Vol. 18, No. 5, pp.375-405.

Ray, G., Muhanna, W.A. and Barney, J.B. (2005) 'Information technology and the performance of the customer service process: a resource-based analysis', MIS Quarterly, Vol. 29, No. 4, pp.625-652.

Rho, S. and An, J. (2007) 'Evaluating the efficiency of a two-stage production process using data envelopment analysis', International Transactions in Operational Research, Vol. 14, No. 5, pp.395-410.

Richardson, V. and Zmud, R.W. (2002) 'Systematic investor biases regarding stock market returns following information technology expenditures', Working paper, University of Oklahoma.

Sambamurthy, V., Bharadwaj, A. and Grover, V. (2003) 'Shaping agility through digital options: reconceptualizing the role of information technology in contemporary firms', MIS Quarterly, Vol. 27, No. 2, pp.237-263.

Sarıca, K. and Or, I. (2007) 'Efficiency assessment of Turkish power plants using data envelopment analysis', Energy, Vol. 32, No. 8, pp.1484-1499.

Scott, T. (2000) 'A framework for measuring the efficiency of organizational investments in information technology using data envelopment analysis', Omega, Vol. 28, No. 2, pp.125-141.

Seiford, L.M. and Zhu, J. (1999) 'Profitability and marketability of the top 55 U.S. commercial banks', Management Science, Vol. 45, No. 9, pp.1270-1288.

Sexton, T.R. and Lewis, H.F. (2003) 'Two-stage DEA: an application to major league baseball', Journal of Productivity Analysis, Vol. 19, Nos. 2-3, pp.227-249.

Shafer, S.M. and Byrd, T.A. (2000) 'A framework for measuring the efficiency of organizational investments in information technology using data envelopment analysis', Omega, Vol. 28, No. 2, pp.125-141. 
Siegel, D. (1997) 'The impact of computers on manufacturing productivity growth: a multiple-indicators, multiple causes approach', Review of Economics and Statistics, Vol. 79, No. 1, pp.68-78.

Soh, C. and Markus, M.L. (1995) 'How IT creates business values: a process theory synthesis', Proceedings of the Sixteenth International Conference on Information Systems, Amsterdam, 10-13 December, pp.29-41.

Stratopoulos, T. and Dehning, B. (2000) 'Does successful investment in information technology solve the productivity paradox?', Information and Management, Vol. 38, No. 2, pp.103-117.

Subramani, M.R. and Walden, E. (2001) 'The impact of e-commerce announcements on the market value of firms', Information Systems Research, Vol. 12, No. 2, pp.135-154.

Triplett, J.E. (1999) 'The Solow productivity paradox: what do computers do to productivity?', Canadian Journal of Economics, Vol. 32, No. 2, pp.309-334.

Wang, C.H., Gopal, R. and Zionts, S. (1997) 'Use of data envelopment analysis in assessing information technology impact on firm performance', Annals of Operations Research, Vol. 73, No. 1, pp.191-213.

Yang, Z. (2006) 'A two-stage DEA model to evaluate the overall performance of Canadian life and health insurance companies', Mathematical and Computer Modelling, Vol. 43, Nos. 7-8, pp.910-919.

Zhu, J. (2000) 'Multi-factor performance measure model with an application to Fortune 500 companies', European Journal of Operational Research, Vol. 123, No. 1, pp.105-124.

Zhu, J. (2002) Quantitative Models for Performance Evaluation and Benchmarking: Data Envelopment Analysis with Spreadsheets, Boston: Kluwer Academic.

\section{Note}

1 Some of the data presented in this study are changed to protect the anonymity of the power plants. 